\title{
Reclamation of the Polymer-Flooding Produced Water
}

\author{
Chunjie HAN, Yang LIU, Tan ZHAO, Guolin JING \\ Electronic Science College, Daqing Petroleum Institute, Daqing, China \\ E-mail: jglhgd@163.com \\ Received January 6, 2009; revised February 20, 2009; accepted February 23, 2009
}

\begin{abstract}
In order to resolve the discharge problem of the polymer-flooding produced water (PFPW) in crude oil extraction, the PFPW was treated by a four-grade and four-segment (four GS) electrodialysis reversal(EDR) set-up. The testing results show that the treated PFPW has two kinds, one is the diluted treated PFPW, the total dissolved solids (TDS) of the diluted treated PFPW is less than the original PFPW, the diluted treated PFPW is feasible for confecting polymer solution; another one is the concentrated treated PFPW, the TDS of the concentrated treated PFPW exceeds the original PFPW, the concentrated treated PFPW is feasible for replacing the PFPW as the injecting water in the water-flooding process for high permeability layer. This treatment technology can not only decrease environment pollution resulted by the PFPW discharge, but also achieve closed-circuit of the water resource during crude oil extraction by using polymer flooding technology.
\end{abstract}

Keywords: Polymer-Flooding Produced Water, Total Dissolved Solids, Electrodialysis, Treatment

\section{Introduction}

In crude oil extraction, water can be injected into the stratum to drive the crude oil out of the ground, which is often termed as water flooding process or secondary oil extraction. The oil content would decrease after the secondary oil extraction is operated for some time. In order to improve the oil recovery, polymer flooding (injected water containing polymer) and alkaline- surfactant-polymer flooding (injected water containing alkaline, surfactant and polymer) would subsequently be used, which is often called as tertiary oil extraction. Industrial experiences show that polymer flooding can enhance oil recovery by up to $12 \%$ and plays a key role in the oil exploitation $[1,2]$. This technology has been widely used in Daqing oilfield in China in recent years [3-5]. Recent statistics show that oil production by polymer flooding in China reached $10 \times 10^{6}$ ton in 2006, and Daqing oilfield has the largest polymer flooding project in the world.

Figure 1 illustrates process of tertiary oil extraction by polymer flooding and treatment of produced water. A large quantity of a polymer (hydrolyzed polyacrylamide, HPAM) is dissolved in water to increase the solution viscosity before water is injected into the stratum through water wells. The HPAM solution with some crude oil is then extracted from the oil wells. The produced liquid becomes produced water (oily wastewater) after dehydration process using three-phase separators. And the produced water becomes polymer- flooding produced water (PFPW) after it is further treated. The PFPW contains polymer, oil, calcium, magnesium, Carbonate and so on.

After the removal of oil, grease, suspended solids, and organic compounds, the PFPW is our investigative content. There are few effects of HPAM on treatment of PFPW by four GS EDR technology and the effects of HPAM has been described in another paper [6]. The high total dissolved solids (TDS) concentration in produced water still poses a challenge in the treatment for beneficial use. It is well known that there are some corresponding relation between the viscosity and the TDS of PFPW. When TDS is a little higher, correspondingly viscosity is a little lower, vice versa [7]. However viscosity is one of the most important parameters to achieve polymer flooding. Simulated experimental results showed when TDS is less than the one of surface water, whether at the aspect of viscidity or shear-resistance ability, the quality of the PFPW can always meet all the conditions for oilfield polymer solution confection. So we 
can think removing TDS is the key problem to actualize the PFPW reused. Separation technologies that are currently available for desalting produced water include filtration with bentonite membrane [8], reverse osmosis $\left[9,10^{-12}\right]$, and electrodialysis (ED) [6]. Most of the published work on the removal of TDS from oilfield produced water was addressed with the use of reverse osmosis, few scaled-up tests of electrodialysis has been performed for this application [6]. The reduction of TDS in produced water with ED is the focal point of this paper.

In ED, electrolytes are transferred through a system of solutions and ion-exchange membranes by an applied electric potential gradient. An ED stack consists of cation-exchange membranes, which are permeable to positively charged ions but not to negatively charged ones, and anion-exchange membranes, which are permeable to negatively charged ions but not to positively charged ones. In the stack, cation-exchange membranes alternate with anion-exchange membranes to form solution compartments. When an electrical potential is applied between the electrodes at the end of the stack, all cations in the solution circulating through the stack tend to move toward the cathode and all the anions tend to migrate toward the anode. The cations that migrate through cation exchange membranes toward the cathode are rejected by anion-exchange membranes; simultaneously, the anions that pass through anion-exchange membranes toward the anode are rejected by cation- exchange membrane. As a result, ion depletion and concentration are accomplished in alternating solution compartments. The diluate streams from the alternating compartments are combined and distributed back to the same compartments to continuously remove the ions from the diluate. An analogous process occurs to continuously increase the ions in the concentrate [13].

In order to reduce the risk of caused scaling by concentration polarization and suspended solids adsorbing, this set-up adopts four-grade and four-segment (four GS) electrodialysis reversal (EDR) technology to desalinate the PFPW. Through the test results, the conductivity of the treated PFPW was under $1.3 \mathrm{mS} / \mathrm{cm}$ and the energy consumption for producing $1 \mathrm{~m}^{3}$ diluted treated PFPW was less than $1 \mathrm{~kW} \cdot \mathrm{h}$. keeping the flowrate ratio of concentrated and diluted treated PFPW as $1: 1$, as well as varying the flowrate and voltage, the removal rate under different flowrate was measured. The optimal operating conditions were studied. In optimal conditions, the available uses of the diluted treated PFPW and the concentrated treated PFPW were analyzed.

\section{Experiment}

The test equipment is shown in Figure 2. This set-up consists of feed water pump, drainage pump, feed water pipes, draining pipes, flowmeters, four GS EDR membrane stack (the active area of a membrane is $400 \times 1600$ $\mathrm{mm}^{2}$. There are 4 segment membrane stacks. Each segment membrane stack consists of 75 anion-exchange, 76 cation-exchange membranes and 150 spacers which are arrayed alternately), 5pairs of Ti-Ru electrodes, automatic control cabinet, rectifier cabinet, online conductivity meter, $20 \mathrm{~kW}$ transformer, air compressor, draining tank and pickling tank.

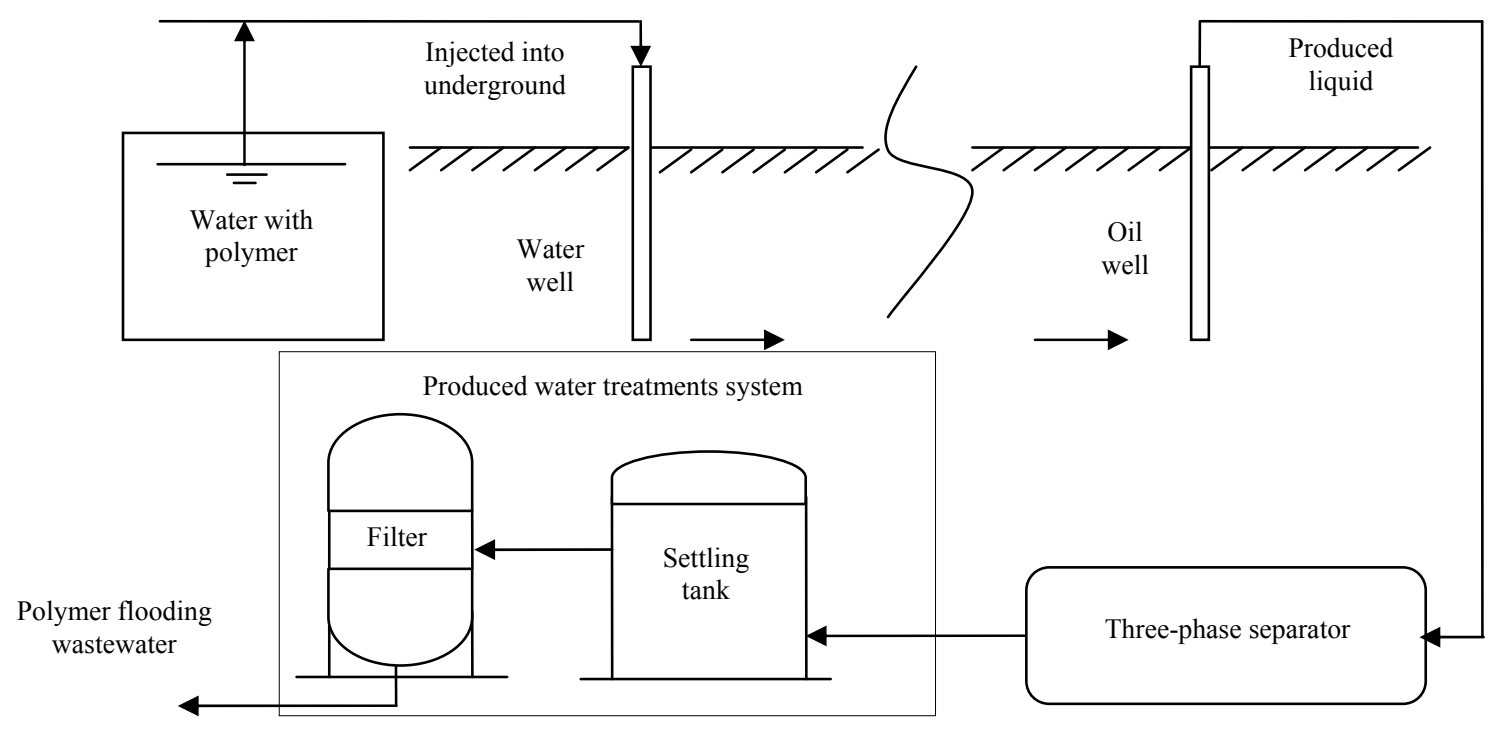

Figure 1. Process of tertiary oil extraction by polymer flooding and treatment of produced water. 


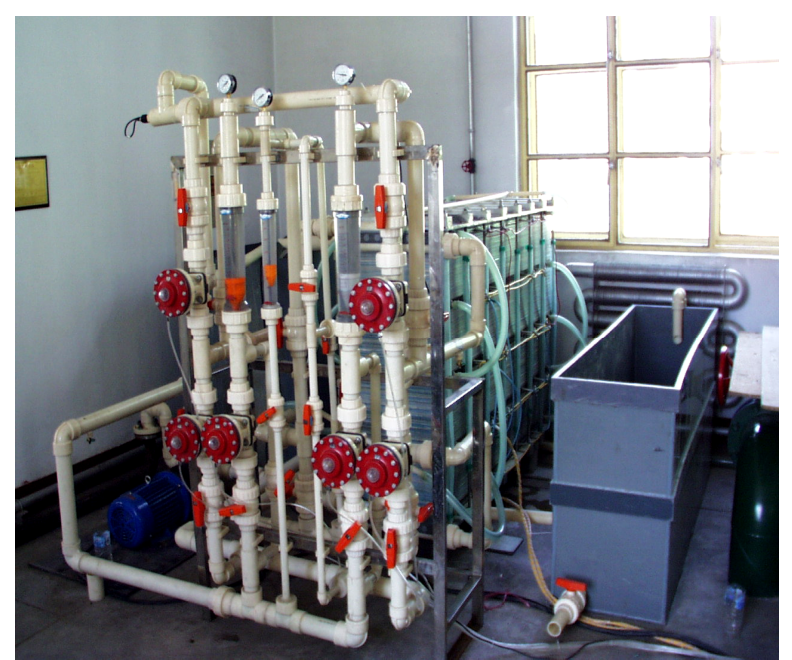

Figure 2. Test equipment.

\section{Results and Discussion}

Firstly, electrical potential difference and feed water were applied in the set-up. Under the condition of adopting four GS electrodialysis reversal technology, keeping the flowrate ratio of concentrated and diluted treated PFPW as 1:1, as well as varying the flowrate and voltage, the removal rate under different flowrate was measured. The results are shown in Figure 3.

Under this operating condition, when the flowrate was $3 \mathrm{~m}^{3} / \mathrm{h}$, the minimal removal rate of TDS was $77.4 \%$; the maximal removal rate of TDS was $94.4 \%$. When the flowrate was $4 \mathrm{~m}^{3} / \mathrm{h}$, the minimal removal rate of TDS was $75.8 \%$; the maximal removal rate of TDS was $90.6 \%$. When the flowrate was $5 \mathrm{~m}^{3} / \mathrm{h}$, the minimal removal rate of TDS was $75.8 \%$; the maximal removal rate of TDS

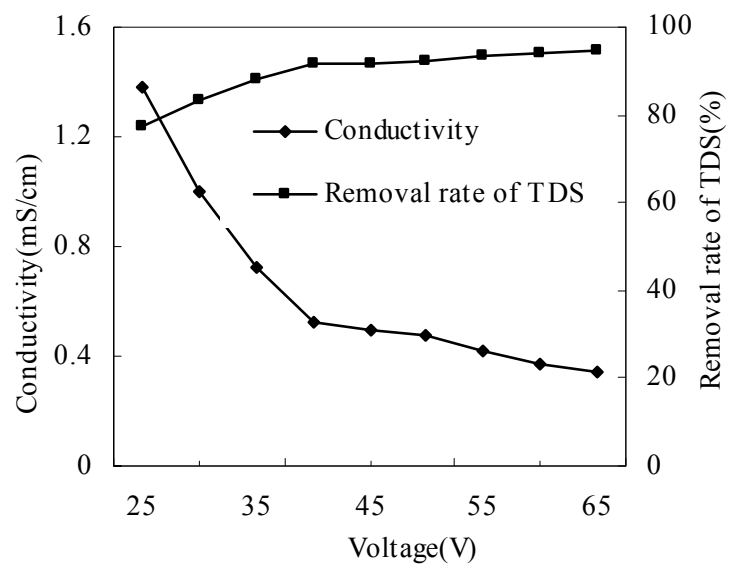

Figure 3(a). Four GS operation effect under $3 \mathrm{~m}^{3} / \mathrm{h}$ flowrate. was $84.3 \%$. According to the test results, it is analyzed that their common operating characteristics are that with the rise of operating voltage, the removal rate of TDS increases, but the treated PFPW conductivity decreases; at the same voltage, with the rise of the flowrate, the removal rate of TDS decreases, the greater the flowrate was, the lower the removal rate of TDS was; at the same removal rate, the greater the flowrate was, the higher the applied voltage was.

Because the set-up pressure can only provide the flowrate of $11 \mathrm{~m}^{3} / \mathrm{h}$, in order to determine the maximum treating capacity, the flowrate of the concentrated treated PFPW was reduced, the flowrate of the diluted treated PFPW was increased, and the total flowrate was $11 \mathrm{~m}^{3} / \mathrm{h}$. A testing (the flowrate of the concentrated treated PFPW was $4 \mathrm{~m}^{3} / \mathrm{h}$, the diluted treated PFPW was $6 \mathrm{~m}^{3} / \mathrm{h}$, the rinse solution was $1 \mathrm{~m}^{3} / \mathrm{h}$.) was carried out. The results were shown in Figure 4. When the flowrate of the diluted treated PFPW was $6 \mathrm{~m}^{3} / \mathrm{h}$, its conductivity can be under $1.3 \mathrm{mS} / \mathrm{cm}$ by increasing the voltage, but the energy consumption reached $1.4 \mathrm{~kW} \cdot \mathrm{h} / \mathrm{m}^{3}$, which exceeds the design standards. So the maximum treating capacity of the diluted treated PFPW was $5 \mathrm{~m}^{3} / \mathrm{h}$.

The lower the flowrate of concentrated treated PFPW, the higher the concentration ratio. Due to that reason, when the concentration difference is much bigger, the selectivity of membranes would be decreased, the reverse osmosis of TDS be increased, which results in the decrease of current efficiency, and the decrease of TDS removal rate. Under the condition of adopting four GS, when the flowrate of the rinse solution was $1 \mathrm{~m}^{3} / \mathrm{h}$ and the diluted treated PFPW was $5 \mathrm{~m}^{3} / \mathrm{h}$, varying the flowrate of the concentrated treated PFPW, the energy consumption was determined at different ratio of concentrated and diluted treated PFPW.

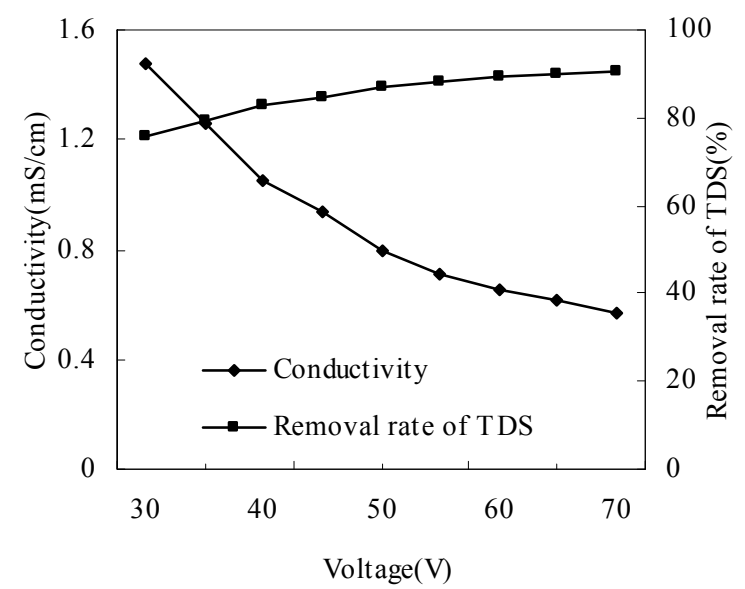

Figure 3(b). Four GS operation effect under $4 \mathrm{~m}^{3} / \mathrm{h}$ flowrate. 


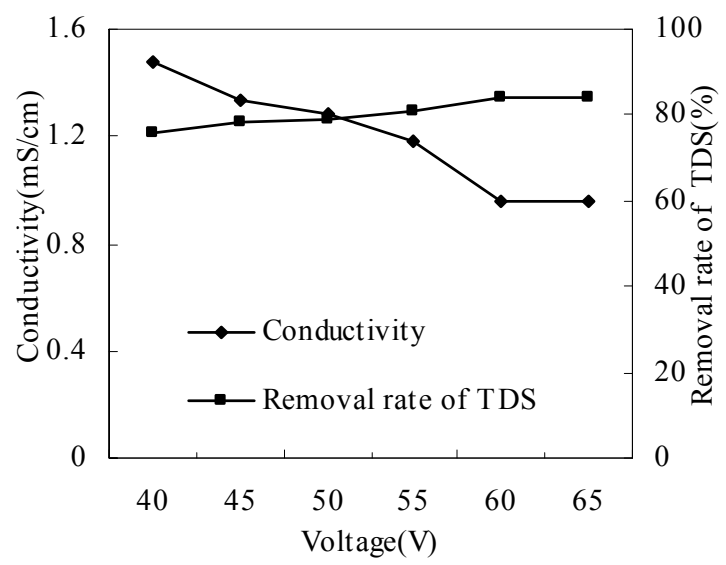

Figure 3(c). Four GS operation effect under $5 \mathrm{~m}^{3} / \mathrm{h}$ flowrate.

As shown in Figure 5, when the flowrate of the diluted treated PFPW was $5 \mathrm{~m}^{3} / \mathrm{h}$, reducing the flowrate of the concentrated treated PFPW, the energy consumption of the same removal rate of TDS were less than 1 $\mathrm{kW} \cdot \mathrm{h} / \mathrm{m}^{3}$. But the basic trend is that the lower the flowrate of the concentrated treated PFPW, the higher the energy consumption. When the conductivity achieved $1.3 \mathrm{mS} / \mathrm{cm}$, which is the stated value, and the flowrate of the diluted treated PFPW was $5 \mathrm{~m}^{3} / \mathrm{h}$, the energy consumption was the lowest. When the flowrate of the concentrated treated PFPW was $2 \mathrm{~m}^{3} / \mathrm{h}$, the diluted treated PFPW was $5 \mathrm{~m}^{3} / \mathrm{h}$ and the energy consumption was $0.89 \mathrm{~kW} \cdot \mathrm{h} / \mathrm{m}^{3}$. In order to enhance the production rate and meet the request for energy consumption, the selected flowrate of the concentrated and the diluted treated PFPW was $2 \mathrm{~m}^{3} / \mathrm{h}$ and $5 \mathrm{~m}^{3} / \mathrm{h}$ respectively.

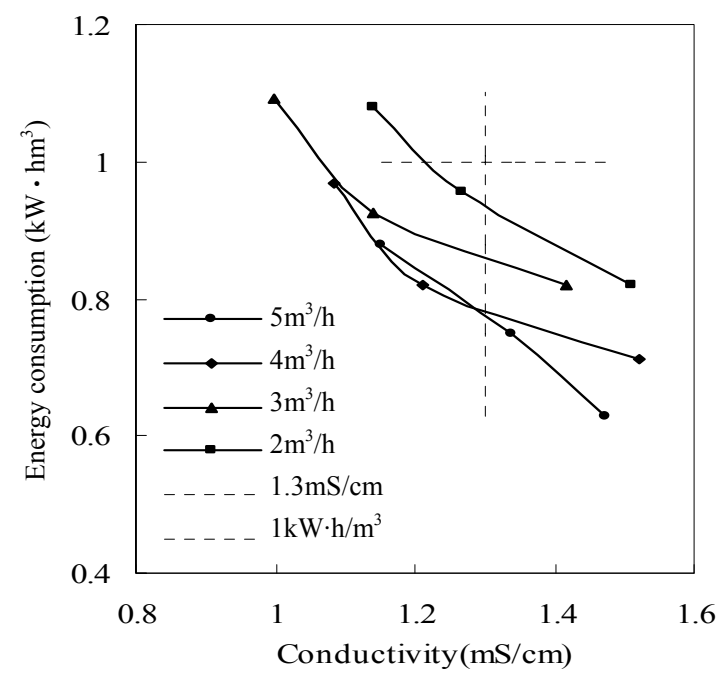

Figure 5. Relation between conductivity and energy consumption at different flowrate of the concentrated treated PFPW.

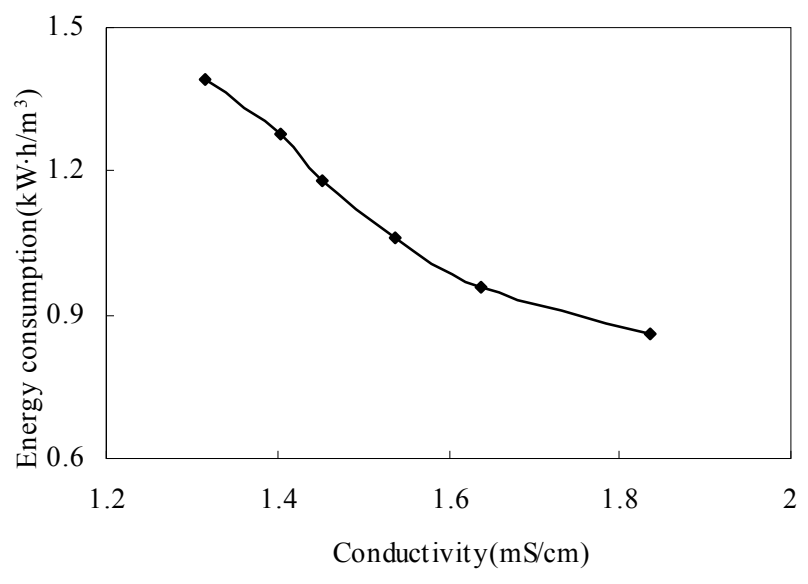

Figure 4. Relation between conductivity and energy consumption.

Under the condition of adopting four GS, the optimal operating conditions are: the flowrate of the rinse solution was $1 \mathrm{~m}^{3} / \mathrm{h}$, the diluted treated PFPW was $5 \mathrm{~m}^{3} / \mathrm{h}$, and the concentrated treated PFPW was $2 \mathrm{~m}^{3} / \mathrm{h}$.

In optimal operating conditions, the treated PFPW has two kinds, one is the diluted treated PFPW whose TDS is less than the original PFPW, the diluted treated PFPW is feasible for confecting polymer solution; another one is the concentrated treated PFPW whose TDS exceeds the original PFPW, the concentrated treated PFPW is feasible for replacing the PFPW as the injecting water in the water-flooding process for high permeability layer. The water quality data about the PFPW, the diluted treated PFPW and the concentrated treated PFPW are presented in Table 1.

The $\mathrm{pH}$ values of three types of water are different, as shown in Table 1 . The $\mathrm{pH}$ of the diluted treated PFPW was lower than the original PFPW, but the $\mathrm{pH}$ of the concentrated treated PFPW was higher than the original PFPW. This is because after the original PFPW was treated by the ED set-up, the most $\mathrm{HCO}_{3}{ }^{-}$that influencing the $\mathrm{pH}$ of the original PFPW was concentrated into the concentrated treated PFPW. The $\mathrm{HCO}_{3}{ }^{-}$of the diluted treated PFPW decreased from $2803 \mathrm{mg} / \mathrm{L}$ (in the PFPW) to less than $1000 \mathrm{mg} / \mathrm{L}$. So the $\mathrm{pH}$ of the diluted treated PFPW was deceased due to the reduction of $\mathrm{HCO}_{3}^{-}$. Finally the $\mathrm{pH}$ of the diluted treated PFPW was 7.78 , which is alkaline, and it would not lead any corrosion to the preparation and injection equipments and pipelines. Seen from Table 1, the concentrations of some divalent ions such as $\mathrm{Ca}^{2+}, \mathrm{Mg}^{2+}$ are little, so they can not cause scaling when the concentrated treated PFPW was used as the injecting water in the water-flooding process for high permeability layer. It fully meets the $\mathrm{pH}$ requirement of confecting polymer solution in oilfields. Therefore, the diluted treated PFPW can be used to confect polymer solution. The $\mathrm{pH}$ of the concentrated PFPW is a little higher than the original PFPW. The TDS of the concen- 
Table 1. The characteristics of PFPW being used in the test.

\begin{tabular}{|c|c|c|c|}
\hline & Original PFPW & Diluted treated PFPW & Concentrated treated PFPW \\
\hline $\mathrm{pH}$ & 8.50 & 7.78 & 8.80 \\
\hline $\mathrm{K}^{+}+\mathrm{Na}^{+}(\mathrm{mg} / \mathrm{L})$ & 1474.5 & 245.2 & 2398.8 \\
\hline $\mathrm{Ca}^{2+}(\mathrm{mg} / \mathrm{L})$ & 16.0 & 8.0 & 44.1 \\
\hline $\mathrm{Mg}^{2+}(\mathrm{mg} / \mathrm{L})$ & 4.9 & 2.4 & 2.4 \\
\hline $\mathrm{Cl}^{-}(\mathrm{mg} / \mathrm{L})$ & 895.4 & 97.5 & 1524.9 \\
\hline $\mathrm{SO}_{4}{ }^{2-}(\mathrm{mg} / \mathrm{L})$ & 96.1 & 67.3 & 38.4 \\
\hline $\mathrm{HCO}_{3}^{-}(\mathrm{mg} / \mathrm{L})$ & 2135.7 & 427.2 & 3417.1 \\
\hline $\mathrm{CO}_{3}{ }^{2-}(\mathrm{mg} / \mathrm{L})$ & 75.0 & 0.0 & 180.1 \\
\hline Polymer (mg/L) & 150.3 & 146.7 & 151.4 \\
\hline Suspended solids (mg/L) & 3.0 & 2.8 & 2.9 \\
\hline Oil (mg/L) & 2.6 & 2.7 & 2.8 \\
\hline TDS (mg/L) & 4697.6 & 847.6 & 7605.7 \\
\hline
\end{tabular}

trated treated PFPW was about twice of the PFPW. Because there is no specific requirement for the TDS in the injecting water for water flooding in the high permeability layer, the concentrated PFPW with a little higher $\mathrm{pH}$ than the PFPW would not bring any effect on water injection production. Therefore the concentrated treated PFPW is feasible to be used to replace the original PFPW as the flooding water in the high permeability layer.

\section{Conclusions}

This set-up adopts four-grade and four-segment (four GS) electrodialysis reversal technology to desalinate the PFPW. Under the condition of adopting four-grade and four-segment, keeping the ratio of concentrated and diluted treated PFPW flowrate as 1:1, as well as varying the flowrate and voltage, the removal rate under different flowrate was measured. The optimal operating conditions were studied. In optimal operating conditions, the available uses of the diluted treated PFPW and the concentrated treated PFPW were analyzed. Based on the test results, the optimal operating conditions are as follows: the flowrate of the rinse solution was $1 \mathrm{~m}^{3} / \mathrm{h}$, the diluted treated PFPW was $5 \mathrm{~m}^{3} / \mathrm{h}$, and the concentrated treated PFPW was $2 \mathrm{~m}^{3} / \mathrm{h}$. In optimal conditions, the testing results show that the treated PFPW has two kinds, one is the diluted treated PFPW whose TDS is less than the original PFPW, the diluted treated PFPW is feasible for confecting polymer solution; another one is the concentrated treated PFPW whose TDS exceeds the original PFPW, the concentrated treated PFPW is feasible for replacing the original PFPW as the injecting water in the waterflooding process for high permeability layer. This treatment technology can not only decrease environment pollution resulted by the PFPW discharge, but also achieve closed-circuit of the water resource during crude oil extraction by using polymer flooding technology.

\section{References}

[1] D. K. Han, C. Z. Yang, Z. Q. Zhang, Z. H. Lou, and Y. I. Chang, Journal of Petroleum Science and Engineering, 22 (1-3), pp. 181-188, 1999.

[2] D. M. Wang, J. C. Cheng, and J. Z. Wu, SPE 49018, pp. 313-317, 1998.

[3] Q. M. Wang, Petroleum Geology, and Oilfield Development in Daqing, 18 (4), pp. 1-5, 1999.

[4] K. C. Taylor, SPE 29008, pp. 675-690, 1995.

[5] T. L. Chen, Z. Y. Song, Y. Fan, C. Z. Hu, L. Qiu, and J. X. Tang, SPE Reservoir Evaluation and Engineering, 1 (1), pp. 24-29, 1998.

[6] G. L. Jing, X. Y. Wang, and C. J. Han, "The effect of oilfield polymer-flooding wastewater on anion- exchange membrane performance," Desalination, 220, pp. 386-393 (Proceedings Greece 2007), 2008.

[7] R. B. Zhao and X. G. Yue, "Flowing characteristics of 2-acrylamide-2-methyl propane-sulfonic-acid copolymer solution in porous medium," Journal of Acta Petrolei Sinica, 26 (2), pp. 85-97, 2005.

[8] L. Liangxiong, T. M. Whitworth, and R. Lee, "Separation of inorganic solutes from oil-field produced water using a compacted bentonite membrane," Journal of Membrane Science, 217, pp. 215-225, 2003.

[9] G. F. Doran, F. H. Carini, D. A. Fruth, J. A. Drago, and L. Y. C. Leong, "Evaluation of technologies to treat oil field produced water to drinking water or reuse quality," Proceedings of the Annual SPE Technical Conference, San Antonio, Texas, 1997. 
[10] J. Pellegrino, C. Gorman, and L. Richards, "A speculative hybrid reverse osmosis electrodialysis unit operation," Desalination, 214, pp. 11-30, 2007.

[11] C. Murray-Gulde, J. E. Heatley, T. Karanfil, J. H. Rodgers Jr., and J. E. Myers, "Performance of a hybrid reverse osmosis-constructed wetland treatment system for brackish oil field produced water," Water Research, 37, pp. 705-713, 2003.
[12] R. Bradley, "Pilot testing high efficiency reverse osmosis on gas well produced water," Proceedings of the International Water Conference (61st Annual Meeting), Pittsburg, PA, 2000.

[13] T. Sirivedhin, J. McCue, and L. Dallbauman, "Reclaiming produced water for beneficial use: Salt removal by electrodialysis," Journal of Membrane Science, 243, pp. 335-343, 2004. 